\title{
Mice vaccinated with a non-virulent, aromatic- dependent mutant of Salmonella choleraesuis die from challenge with its virulent parent but survive challenge with Salmonella typhimurium
}

\author{
N. A. NNALUE \\ Department of Microbiology and Immunology, Stanford University School of Medicine, Stanford, CA 94305, \\ USA
}

\begin{abstract}
Summary. BALB/c mice given a live vaccine of an aroA mutant of Salmonella choleraesuis by intraperitoneal (i.p.) injection were not protected against i.p. challenge with its virulent parental strain but were protected against i.p. challenge with either of two virulent strains of Salmonella typhimurium (O [1],4,[5],12). Vaccination with a live vaccine of $S$. typhimurium aro $A$ protected against challenge with $S$. typhimurium but not with $S$. choleraesuis. Intraperitoneal administration of either aroA strain evoked high levels of serum antibody against the homologous lipopolysacharide (LPS) as determined by an enzyme immunoassay. Sera from vaccinated mice also reacted with heterologous LPS but at dilutions at least seven-fold lower than homologous endpoint titres. The vaccination schedule employed with either live-vaccine strain conferred an equal degree of resistance to challenge with Listeria monocytogenes. After mixed infection of mice with equal numbers of virulent $S$. typhimurium and $S$. choleraesuis by the i.p. route, the former was isolated in numbers at least 50000 times greater than the latter from the liver and spleen between days 1 and 5 . When mice were vaccinated i.p. with $S$. choleraesuis aro $A, L$. monocytogenes or $P$. multocida before mixed infection, neither serotype showed more than a slight predominance in the liver and spleen during the same period. Thus, in relative terms, vaccination with $S$. choleraesuis aro $A$ or inoculation with unrelated bacteria suppressed the growth of virulent $S$. typhimurium in mice but allowed virulent $S$. choleraesuis to multiply. These results clearly show that $S$. choleraesuis $38_{1}$ can multiply to kill immunised BALB/c mice.
\end{abstract}

\section{Introduction}

Salmonella choleraesuis is a highly virulent member of the genus Salmonella which is host-adapted for swine. It is highly invasive in man, but unlike other invasive salmonellae, such as the typhoid and paratyphoid organisms, it infects man without involving the intestines (Weissbluth et al., 1981). Human infection with $S$. choleraesuis is characterised by septicaemia, multiple abscesses in internal organs and osteomyelitis, and is associated with a higher mortality rate than are other salmonella infections (MacCready et al., 1957; Saphra and Winter, 1957; Weissbluth et al., 1981). Except in Hong Kong (Huang and Lo, 1967) S. choleraesuis is

Received 6 June 1989; accepted 24 Sept. 1989.

Present address: Department of Clinical Bacteriology, F72, Karolinska Institute, Huddinge University Hospital, 14186 Huddinge, Sweden. not a common cause of disease in man. The $O 6,7$ antigen of $S$. choleraesuis is known to confer less virulence for mice than the O 4,12 antigen of $S$. typhimurium (Valtonen et al., 1975; Valtonen, 1977). This is, at least partly, a result of $O 6,7$ activating complement by the alternative pathway more rapidly than $\mathrm{O} 4,12$ (Liang-Takasaki et al., 1983), which promotes rapid phagocytosis (Liang-Takasaki et al., 1982) and intracellular killing of $S$. choleraesuis and other bacteria that carry the $\mathrm{O} 6,7$ antigen by peritoneal macrophages (Nnalue and Stocker, 1987b; Saxen et al., 1987). These facts are inconsistent with the unusually high mortality rates associated with infections caused by this organism.

Protective response against infection with such salmonella serotypes as $S$. typhimurium and $S$. enteritidis is largely serogroup-specific (Ornellas et al., 1970; Lyman et al., 1979). However, Salmonella strains of different serotypes have common anti- 
genic determinants in their outer-membrane proteins (Kuusi et al., 1979; Svenson et al., 1979) and in the LPS core (McCabe, 1972; McCabe et al., 1977) which also elicit a protective response. Cross protection between serogroups (Smith, 1965; Smith and Halls, 1966; Collins, 1968; Schlecht, 1981) is, therefore, frequently observed. Moreover salmonellae (Blanden et al., 1966; Eisenstein et al., 1984), like other facultatively intracellular parasites (Mackaness, 1964; Zinkernagel, 1976), elicit a nonspecific protective response against unrelated bacteria. However, the strongest protective effects are usually directed against serotypes of the same $\mathrm{O}$ antigen composition as vaccine strains (Ornellas et al., 1970; Lyman et al., 1979). This should also be the case in natural infections.

We have found that live-vaccine strains ( $\mathrm{galE}$ or aro $A$ mutants) of $S$. choleraesuis did not protect salmonella-susceptible inbred mice (BALB/c and C57BL/6) against challenge with virulent strains (Nnalue and Stocker, 1987a), and that non-virulent bacteria with $\mathrm{O} 6,7$ LPS did not persist in vivo after intraperitoneal (i.p.) inoculation (Nnalue and Stocker, 1987b). These mouse strains are readily infected with salmonellae because they carry the susceptible allele, Itys, of a genetic locus that determines ability to control multiplication of salmonellae in the liver and spleen. In this study I investigate whether the observed lack of protection was due to complete or relative failure of the protective response or to the ability of $S$. choleraesuis to multiply in mice that have mounted a good immunological response.

\section{Materials and methods}

\section{Media}

The media used were Blood Agar Base (CM55), Nutrient Broth (CM67) (Oxoid) and MacConkey Agar and Base (Difco) supplemented with the desired carbohydrate $(5 \mathrm{~g} / \mathrm{L})$.

\section{Bacterial strains}

Bacterial strains and their sources or relevant references are listed in table $\mathrm{I}$. The wild type strain of $S$. choleraesuis, 38, (Griffith and Kramer, 1981) was obtained from Dr R. Griffith of Iowa State University, Ames, Iowa. A mouse- and calf-virulent strain of $S$. typhimurium, strain UCD108-11 (Smith et al., 1984), was obtained from Dr B. Smith of The University of California at Davis. S. typhimurium M7471 is of the FIRN biotype and was isolated from a case of food poisoning in England in 1958 (Ornellas and Stocker, 1974). The O-antigenic composition of these bacteria is: strain $38_{1} \mathrm{O}_{6}, 7$; UCD108-11 O 1,4,12; and strain
M7471 O 4,5,12. The construction of non-virulent, aromatic-dependent, derivatives of these strains has been described previously (table I).

\section{Mouse vaccination and challenge}

Specific-pathogen-free BALB/c mice came from the Department of Radiology, Stanford University, Stanford, CA. Live-vaccine strains were grown overnight in nutrient broth and held for $24 \mathrm{~h}$ at $4^{\circ} \mathrm{C}$ while viable counts were determined by plating. Broth cultures were then diluted in saline and used for inoculation. The livevaccination regimen consisted of two doses, $(2-5) \times 10^{6}$ cfu/injection, given i.p. in $0.1 \mathrm{ml}$ of saline 3 weeks apart. Vaccinated mice and unvaccinated controls were challenged i.p. with virulent strains 6 or 7 weeks after the second dose and observed for 6 weeks after challenge. Dead animals were examined post mortem for gross liver pathology and for re-isolation of the challenge strain. The growth of bacteria in the livers and spleens of vaccinated mice after i.p. challenge with virulent strains was studied. The mice were given three doses of live vaccine at 2week intervals and challenged i.p. with $2.5 \times 10^{5} \mathrm{cfu}$ of each virulent strain 12 days after the last vaccination. Three mice each were killed on days 1, 3 and 6 after challenge to determine the numbers of each strain in the liver and spleen. Their livers and spleens were homogenised with a Colworth stomacher (Seward) in $5 \mathrm{ml}$ of saline, then diluted and plated on MacConkey agar. MacConkey base agar with arabinose $5 \mathrm{~g} / \mathrm{L}$ was used for plating in mixed infections to differentiate colonies of $S$. choleraesuis (arabinose negative) from those of $S$. typhimurium (arabinose positive). Listeria monocytogenes and Pasteurella multocida do not grow on this medium which allowed isolation and counting of salmonellae alone from livers and spleens also containing these bacteria.

\section{Antibody production and titration}

Humoral response against $O 6,7$ and $O$ 1,4,12 LPS was compared between mice inoculated with each livevaccine strain. The mice were inoculated i.p. with two doses of live vaccine $\left(5 \times 10^{6} \mathrm{cfu}\right), 3$ weeks apart, and with one dose $\left(5 \times 10^{7} \mathrm{cfu}\right)$ of heat-killed $\left(2 \mathrm{~h}\right.$ at $\left.65^{\circ} \mathrm{C}\right)$ bacteria of the same strain, 6 weeks after the second live dose. They were bled 1 week after the last inoculation. This protocol was designed to simulate conditions in challenge experiments except that killed bacteria were used for the last dose to minimise the presence of live organisms in sera. Anti-LPS antibody in sera was determined by enzyme immunoassay (EIA) with LPS from $S$. choleraesuis $38_{1}$ and $S$. typhimurium UCD108-11 prepared by the method of Darveau and Hancock (1983). The wells of a flat-bottomed microtitration plate were coated overnight at room temperature $\left(c .20^{\circ} \mathrm{C}\right)$ with $100 \mu \mathrm{l}$ of LPS solution, $10 \mu \mathrm{g} / \mathrm{ml}$ in $0.1 \mathrm{M}$ sodium carbonate buffer pH $9.6\left(\mathrm{Na}_{2} \mathrm{CO}_{3} 1.59 \mathrm{~g} / \mathrm{L} ; \mathrm{NaHCO}_{3}\right.$ $2.93 \mathrm{~g} / \mathrm{L}$ ). The coating solution was discarded and the plates were washed three times (1 min/wash) with washing buffer $\left(\mathrm{NaCl} 8.0 \mathrm{~g} / \mathrm{L}, \mathrm{KH}_{2} \mathrm{PO}_{4} 0.2 \mathrm{~g} / \mathrm{L}, \mathrm{Na}-\right.$ 
$\mathrm{HPO}_{4} \cdot 12 \mathrm{H}_{2} \mathrm{O} 1 \cdot 15 \mathrm{~g} / \mathrm{L}, \mathrm{KCl} 0 \cdot 2 \mathrm{~g} / \mathrm{L}$, Tween $200.05 \%$ ). Sera for assay were diluted in two-fold steps up to 1 in 10240 in incubation buffer (phosphate-buffered saline,

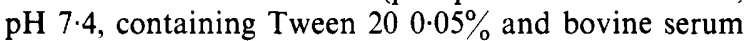
albumin $1 \%$ and added to wells in $100-\mu$ l volumes. Undiluted serum pooled from four unvaccinated mice of the same batch was used as the control. The plate was incubated for $3 \mathrm{~h}$ at $37^{\circ} \mathrm{C}$ and washed as before. Antibody that bound to the LPS in the wells was detected with a commercial EIA kit (Allelix Inc, Toronto, Canada). The urease-labelled rabbit antibody to mouse immunoglobulin was diluted as recommended by the manufacturer and $100 \mu \mathrm{l}$ was added to each well. The plate was incubated for $1 \mathrm{~h}$ at $37^{\circ} \mathrm{C}$ and washed as before. Substrate solution $(100 \mu \mathrm{l})$ was added and the plate was incubated for 30 min at room temperature, then scanned with an EIA reader (Dynatech Laboratories). EIA titres represent the average of results from four mice and are expressed as the serum dilutions that gave an $\mathrm{A}_{595}$ of at least $0 \cdot 1$ unit above that of undiluted normal mouse serum.

\section{Statistical methods}

The data presented in the tables and figures are expressed as geometric means. Standard deviations are also geometric. Fisher's exact test was used at the $95 \%$ level of confidence to analyse the statistical significance of protection data from vaccinated animals compared to unvaccinated controls. It was assumed that the vaccination regimen used would provide some degree of protection against challenge with virulent strains; therefore, only one-tailed statistical tests were done.

\section{Results}

Tests of the protective effects of vaccination with aroA mutants

The protective effects of vaccination with the aromatic-dependent derivatives of $S$. choleraesuis and $S$. typhimurium against homologous and heterologous virulent strains were compared in BALB/c mice (table I). An equal number of unvaccinated control mice of the same age as the test group was used in each challenge experiment. All control mice died from challenge with the doses of virulent bacteria used in this study (data not shown). Two doses of live vaccine were used because it had been shown in a previous study that single doses of aro $A$ mutants of $S$. choleraesuis given as live vaccine i.p. gave no protection (Nnalue and Stocker, 1987a). As shown by Lyman et al. (1979), a live-vaccine would be expected to provide better protection against challenge with a virulent strain of the same $\mathrm{O}$-antigen specificity than against that of another specificity. With the $S$. choleraesuis $38_{1}$ aro $A$ livevaccine (hereinafter designated $S$. choleraesuis aro) the vaccination regimen partially but significantly protected mice against i.p. challenge with 500 LD50 doses of its virulent parent, but did not protect against i.p. challenge with 5000 LD50 doses (table II). Two of six vaccinated mice died from i.p. challenge with 500 LD50 doses of $S$. choleraesuis $38_{1}(\mathrm{p}=0.03)$ whereas eight of 11 mice died from similar challenge with 5000 LD50 doses $(p=0 \cdot 11)$. These results are comparable with those obtained in a previous study with these strains (Nnalue and Stocker, 1986). While not protected against i.p. challenge with 5000 LD50 doses of virulent $S$. choleraesuis, the vaccinated mice were significantly protected against i.p. challenge with at least 5000 LD50 doses of either of the two virulent strains of $S$. typhimurium. None of 11 vaccinated mice died from i.p. challenge with 5000 LD50 doses of M7471

Table I. Bacterial strains and their i.p. LD50 in BALB/c mice

\begin{tabular}{|c|c|c|c|}
\hline Strain & Description & LD50 (cfu, i.p.) & Source or reference \\
\hline 381 & S. choleraesuis wild type & 100 & Nnalue and Stocker, 1986 \\
\hline UCD 108-11 & S. typhimurium wild type & 5 & $\begin{array}{l}\text { Smith et al., 1984; } \\
\text { Nnalue and Stocker, } 1987 a\end{array}$ \\
\hline M7471 & S. typhimurium FIRN wild type & c. 20 & Ornellas and Stocker, 1974 \\
\hline SL2822 & $\begin{array}{l}38^{1} \text { CRR } 426[\text { aro } A 544:: \operatorname{Tn} 10 \\
(\mathrm{Tcs}, \text { non-rev)] zbj-903:: } \mathrm{Tn} 10\end{array}$ & $>5 \times 10^{6}$ & Nnalue and Stocker, $1987 a$ \\
\hline SL2888 & $\begin{array}{l}\text { UCDI08-11 hisC527 CRR426[aroA544 } \\
:: \operatorname{Tn} 10 \text { (Tcs, non-rev)] zbj-903:: Tn } 10 .\end{array}$ & $>5 \times 10^{6}$ & Nnalue and Stocker, $1987 a$ \\
\hline SL3237 & $\begin{array}{l}\text { M7471 rpsL120 CRR401 [aro- } \\
A 544:: \operatorname{Tn} 10(\mathrm{Tcs}, \text { non-rev })]\end{array}$ & $>5 \times 10^{6}$ & $\begin{array}{l}\text { Hoiseth, S. K. Ph.D Thesis } \\
\text { Stanford University, } 1983\end{array}$ \\
\hline EGD & $\begin{array}{l}\text { L. monocytogenes (virulent strain) } \\
P . \text { multocida (avirulent strain) }\end{array}$ & c. $\begin{aligned} 2 \times 10^{3} \\
>10^{7}\end{aligned}$ & $\begin{array}{l}\text { Collins, } 1979 \\
\text { Wong and Kucera, } 1982\end{array}$ \\
\hline
\end{tabular}

CRR, complex genetic rearrangement mutation; non-rev, non-reverting; $z b j$, silent locus at minute 20 of the salmonella chromosome. * The LD50 of L. monocytogenes EGD for BALB/c mice was not determined. It was assumed to be $c .2 \times 10^{3} \mathrm{cfu}$ because this dose killed 24 of 40 mice. 
Table II. Tests of the protective effects of vaccination* with aromatic-dependent Salmonella strains

\begin{tabular}{lcr} 
Challenge strain & Challenge dose, cfu (LD50) & Deaths/to \\
\hline Mice vaccinated with S. choleraesuis aro & & \\
S. choleraesuis & $5 \times 10^{4}(500)$ & {$[2 / 6]$} \\
S. typhimurium M7471 & $5 \times 10^{5}(5000)$ & $8 / 11$ \\
S. typhimurium UCD108-11 & $5 \times 10^{4}(5000)$ & $0 / 11$ \\
Mice vaccinated with S. typhimurium M7471 aro & $5 \times 10^{4}(10000)$ & $3 / 11$ \\
S. choleraesuis & $5 \times 10^{4}(500)$ & $11 / 11$ \\
S. typhimurium M7471 & $5 \times 10^{4}(5000)$ & $0 / 11$ \\
Mice vaccinated with S. typhimurium UCD108-11 aro & & \\
S. choleraesuis & $5 \times 10^{4}(500)$ & $11 / 11$ \\
S. typhimurium UCD108-11 & $5 \times 10^{4}(10000)$ & $0 / 11$
\end{tabular}

${ }^{*}$ Mice were vaccinated i.p. on days 0 and 21 with $5 \times 10^{6} \mathrm{cfu}$ of the appropriate live-vaccine strain and challenged i.p. on day 70.

$\dagger$ Mortality data, except where enclosed in brackets, were pooled from two separate experiments with five and six mice/ group.

and only three mice died in another group of 11 challenged with 10000 LD50 doses of UCD108-11 $(\mathrm{p}=0.0005)$. Thus $S$. choleraesuis aro, used as a live vaccine in BALB/c mice, did not protect against challenge with its parental strain but protected against challenge with $S$. typhimurium.

In contrast, vaccination of mice with the aro $A$ derivative of either strain of $S$. typhimurium protected against challenge with its virulent parent but not against challenge with $S$. choleraesuis (table II). Thus, all vaccinated mice survived i.p. challenge with 5000 or 10000 LD50 doses of the virulent $S$. typhimurium parental strain (table II), but died from challenge with as low as 500 LD50 doses of $S$. choleraesuis. Thus, the cross-protective response between these strains, $S$. choleraesuis versus $S$. typhimurium, seems to be unidirectional. Because UCD108-11 is the more virulent of the two $S$. typhimurium strains and had previously been compared with $S$. choleraesuis $38_{1}$ (Nnalue and Stocker, $1987 a$ ) it was chosen for subsequent comparisons in this study. Its aro $A$ derivative is designated $S$. typhimurium aro.

\section{Immune response in vaccinated mice}

Immune responses were tested in mice vaccinated in almost the same way as those challenged with virulent salmonellae. The average enzyme immunoassay (EIA) titre of antibody against $\mathrm{O}$ 6,7 LPS present in the sera of four mice vaccinated with $S$. choleraesuis aro was 2800 compared to 400 against $\mathrm{O} 1,4,12$ LPS. The four mice vaccinated with $S$. typhimurium aro responded with an average
anti-O 1,4,12 LPS titre of $>10240$ and an average anti-O 6,7 titre of 800 . The level of non-specific resistance at the time of challenge was compared between mice vaccinated with $S$. choleraesuis aro or $S$. typhimurium aro. Mice vaccinated with either live-vaccine strain were found equally resistant to challenge with $L$. monocytogenes strain EDG (table III) and thus appeared to have developed similar levels of non-specific resistance. All of eight mice vaccinated with $S$. choleraesuis aro and seven of eight vaccinated with $S$. typhimurium aro survived challenge with 30 LD50 doses of listeria whereas none of the mice similarly vaccinated with either aro strain survived challenge with 3000 LD50 doses of listeria.

\section{Survival and multiplication of virulent bacteria in} vaccinated and unvaccinated mice

$S$. typhimurium was isolated in numbers at least 50000 times greater than was $S$. choleraesuis from the livers and spleens of unvaccinated mice on days 1,4 and 5 after i.p. administration of $6.5 \times 10^{3} \mathrm{cfu}$ of each organism as a mixed infection (table IV). A similar comparison was done in mice vaccinated with $S$. choleraesuis aro to investigate further why such mice were better protected against challenge with $S$. typhimurium than with $S$. choleraesuis. In the first of two experiments, the mice had more $S$. typhimurium than $S$. choleraesuis in their livers and spleens on both of days 1 and 3 after challenge -36 times more on day 1 and 10 times more on day 3 (fig. 1). On day 6, however, there was 10 times more $S$. choleraesuis than $S$. typhimurium in these organs. 
Table III. Tests of non-specific protective effects against listeria in mice vaccinated* with aromatic-dependent Salmonella strains

\begin{tabular}{llc}
\hline Vaccine strain & $\begin{array}{c}\text { Challenge dose, } \\
\text { cfu (LD50) }\end{array}$ & Deaths/total \\
\hline S. choleraesuis aro & $6 \times 10^{4}(30)$ & $0 / 8$ \\
S. typhimurium aro & $6 \times 10^{6}(3000)$ & $8 / 8$ \\
& $6 \times 10^{4}(30)$ & $1 / 8$ \\
Control & $6 \times 10^{6}(3000)$ & $8 / 8$ \\
& $6 \times 10^{4}(30)$ & $8 / 8$ \\
& $6 \times 10^{6}(3000)$ & $8 / 8$
\end{tabular}

* Mice were vaccinated i.p. on days 0 and 21 with $2 \times 10^{6} \mathrm{cfu}$ and $5 \times 10^{6} \mathrm{cfu}$ respectively of the appropriate live-vaccine strain and challenged i.p. with $L$. monocytogenes on day 65 .

In the second experiment, more $S$. choleraesuis than $S$. typhimurium was recovered from the liver and spleen on similar days; four times more on day 1 after challenge, 10 times more on day 3 and about 400 times more on day 6 (fig. 2). It is not clear why the proportions of $S$. choleraesuis and $S$. typhimurium recovered from mice differed between the two experiments nor why the second group of mice appear to have responded better to vaccination and consequently suppressed the growth of challenge bacteria to a greater degree (by at least a factor of 10 on the respective days). Both groups of mice were purchased as a single batch from the same supplier but those used in the second experiment were 12 weeks old at the start of immunisation

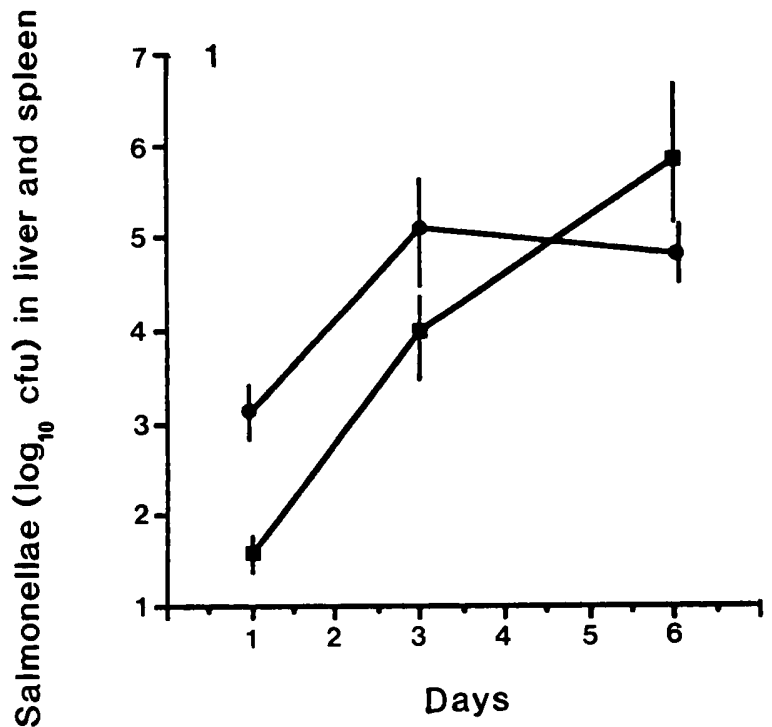

Table IV. Growth of S. choleraesuis $38_{1}$ and $S$. typhimurium UCD108-11 in unvaccinated mice after mixed-infection

\begin{tabular}{|c|c|c|c|}
\hline \multirow[b]{2}{*}{ Day } & \multicolumn{2}{|c|}{$\begin{array}{l}\text { Geometric mean cfu in liver } \\
\text { and spleen }\end{array}$} & \multirow{2}{*}{$\begin{array}{c}\text { Ratio } \\
\text { (SL1260:SL2824) }\end{array}$} \\
\hline & SL2824 & SLl 1260 & \\
\hline 1 & $<30$ & $1.3 \times 10^{4}$ & $>80000$ \\
\hline 4 & $<10^{4}$ & $3.6 \times 10^{8}$ SD 1.5 & $>300000$ \\
\hline 5 & $<3 \times 10^{5}$ & $2 \times 10^{8} \mathrm{SD} 7.2$ & $>50000$ \\
\hline
\end{tabular}

Mice were inoculated ip with a mixed inoculum of $6.5 \times 10^{3} \mathrm{cfu}$ of each strain. Figures represent results from two or three mice.

whereas those for the first experiment were 8 weeks old. The difference in ages could, perhaps, have led to a difference in immunological maturity and consequently to better immune responses in the older mice, as evident from their greater ability to supress the growth of virulent bacteria in the liver and spleen. Irrespective of the causes of these differences, both experiments show that after vaccination the growth of $S$. typhimurium was suppressed to a greater degree than that of $S$. choleraesuis with the result that the overwhelming growth advantage of $S$. typhimurium in nonvaccinated animals was decreased or even reversed. Although equal numbers of both organisms were used in the mixed-infection and mixed-challenge experiments, in fact each mouse was actually given 20 times more LD50 doses of $S$. typhimurium than of $S$. choleraesuis.

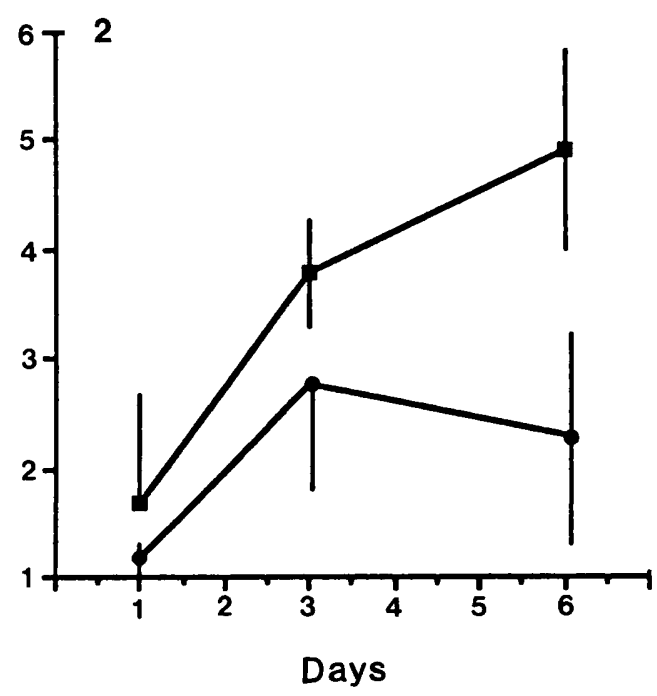

Figs. 1 and 2. Two experiments, comparing the growth of $S$. choleraesuis $38_{1}(\square-\square)$ and $S$. typhimurium UCD108-11 ( $)$ in the livers and spleens of mice vaccinated i.p. with $S$. choleraesuis aro and challenged i.p. with a mixture of $2 \cdot 5 \times 10^{5}$ $\mathrm{cfu}$ of each virulent strain. Each point represents the geometric mean of determinations in three mice. Vertical bars indicate SD. 
Table V. Effect of prior inoculation with L. monocytogenes on the growth of $S$. choleraesuis and $S$. typhimurium in the liver and spleen of mice

\begin{tabular}{c|ccc}
\hline & \multicolumn{2}{|c}{ Geometric mean cfu in liver and spleen } & \\
\cline { 2 - 3 } Day & SL2824 & SL1260 & Ratio (SL1260:SL2824) \\
\hline 4 & $5 \times 10^{6}$ SD 1.92 & $9 \times 10^{7}$ SD 2.94 & 18 \\
5 & $5 \times 10^{8}$ SD 1.90 & $3 \times 10^{9}$ SD 6.27 & 6 \\
\hline
\end{tabular}

Mice were inoculated i.p. with $L$. monocytogenes as follows : $2 \times 10^{3} \mathrm{cfu}$ on the first day, $2 \times 10^{5} \mathrm{cfu}$ on day 7 , and $2 \times 10^{6} \mathrm{cfu}$ on day 14. More than half the mice died from the first dose but the survivors survived the subsequent doses. The mice were challenged on day 21 with a mixture of $5 \times 10^{5} \mathrm{cfu}$ each of $S$. choleraesuis and $S$. typhimurium and $2 \times 10^{6} \mathrm{cfu}$ of L. monocytogenes. Figures represent the geometric means of results from four mice.

Table VI. Effect of prior inoculation with $P$. multocida on the growth of $S$. choleraesuis and $S$. typhimurium in the liver and spleen of mice

\begin{tabular}{c|ccc} 
& \multicolumn{2}{|c}{ Geometric mean cfu in liver and spleen } & \\
\cline { 2 - 3 } Day & SL2824 & SL1260 & Ratio (SL1260:SL2824) \\
\hline 5 & $3 \times 10^{5}$ SD 6.62 & $5 \times 10^{5}$ SD 8.11 & 1.7 \\
\hline
\end{tabular}

Five mice vaccinated once i.p. with $10^{7} \mathrm{cfu}$ of $P$. multocida live vaccine strain were challenged i.p. 8 days later with $5 \times 10^{5} \mathrm{cfu}$ each of $S$. choleraesuis and $S$. typhimurium and killed 5 days after challenge.

To identify more specifically the contribution of non-specific factors in the above results, I compared the growth of $S$. choleraesuis and $S$. typhimurium in mice pre-inoculated with micro-organisms thàt are antigenically unrelated to salmonellae. In one experiment, mice were given three i.p. injections of L. monocytogenes, $2 \times 10^{3} \mathrm{cfu}$ on the first day, $2 \times$ $10^{5} \mathrm{cfu}$ on the eighth day and $2 \times 10^{6} \mathrm{cfu}$ on the fifteenth day. More than half of the mice died after the first injection but the survivors survived the subsequent inoculations. On day 21 they were challenged i.p. with a mixture of $5 \times 10^{5} \mathrm{cfu}$ each of $S$. typhimurium and $S$. choleraesuis together with $2 \times 10^{6} \mathrm{cfu}$ of listeria. When killed 4 or 5 days later, the mice had, on average, less than 20 times more $S$. typhimurium than $S$. choleraesuis on both days (table V). In another experiment, five mice were inoculated i.p. with $10^{7} \mathrm{cfu}$ of a $P$. multocida livevaccine strain 8 days before these were given a mixed infection i.p. with $S$. choleraesuis and $S$. typhimurium. The mice were killed 5 days after challenge and found to have equal numbers of both organisms in their livers and spleens (table VI). Thus, as was observed in mice vaccinated with $S$. choleraesuis aro, the growth of $S$. typhimurium was suppressed more than that of $S$. choleraesuis in mice pre-inoculated with other micro-organisms before mixed infection.

\section{Discussion}

The finding that avirulent derivatives of $S$. choleraesuis were not effective as live vaccines in mice, unlike those of $S$. typhimurium (Nnalue and Stocker, 1987a), formed the basis of the present investigation. The results presented here show that $S$. choleraesuis can multiply to kill mice that have mounted a strong immune response to its antigens. Mice developed high levels of serum anti-O 6,7 LPS antibody after vaccination with $S$. choleraesuis aro but remained susceptible to infection with the virulent strain. The humoral response to LPS seems not to protect against infection by $S$. choleraesuis. This is not the case in infections caused by $S$. typhimurium or $S$. enteritidis in which adoptively transferred B cells (Hochadel and Keller, 1977), serum or monoclonal antibody (Colwell et al., 1984; Carlin et al, 1987; Saxen et al., 1987) or killed or artificial vaccines (Herzberg et al., 1972; Lindberg et al., 1974; Ornellas et al., 1974), which primarily elicit antibody, are protective. The $\mathrm{O}$ antigen is the main protective immunogen against infection with these serotypes and protection is $\mathrm{O}$-antigen-specific 
(Ornellas et al., 1970; Lyman et al., 1979; Carlin et al., 1986). As would be expected from such specificity, vaccination with $S$. typhimurium aro protected against challenge with $S$. typhimurium and did not protect against challenge with $S$. choleraesuis.

The lack of protection against challenge with $S$. choleraesuis in mice vaccinated with $S$. choleraesuis aro is not due to poor elicitation of cellular immunity because such mice were well protected against challenge with $S$. typhimurium and expressed nonspecific resistance against listeria to the same extent as mice vaccinated with $S$. typhimurium aro. The protective effects against $S$. typhimurium in such mice seems to be partly a result of immune response to shared antigens and partly from non-specific activation of immunological defences. Cross protection is often seen between Salmonella serotypes as well as between other enteric bacteria. It is believed to be due mainly to shared antigenic determinants in the LPS core (McCabe, 1972; McCabe et al., 1977) and presumably also in the outer-membrane proteins. The effect of cross reactivity in this study is evident from the fact that the mice vaccinated with $S$. choleraesuis aro were not protected against 3000 LD50 doses of listeria but were protected against 10000 LD50 doses of $S$. typhimurium. Non-specific protection can occur by two mechanisms: endotoxin (LPS)-induced resistance (Abernathy, 1957; Cluff, 1970; Morrison and Ulevitch, 1978; Vuopio-Varkila et al., 1988) from generalised activation of cells of the reticuloendothelial system; and cellular immunity mediated by activated macrophages which, though specifically elicited, is expressed non-specifically (Mackaness, 1964; Levine and Hornick, 1981). Resistance induced by endotoxin is evident soon after inoculation with a gram-negative bacterium and is of short duration. It is probably the mechanism for the resistance to salmonella infection observed in mice vaccinated with $P$. multocida. Cellular immunity, on the other hand, takes at least 2 weeks to develop and should be largely responsible for resistance to salmonella in mice inoculated with listeria. That cross-reactivity and non-specific resistance, both relatively minor protective mechanisms, could protect mice vaccinated with $S$. choleraesuis aro against challenge with as many as 10000 LD50 doses of S. typhimurium is additional evidence that these mice have mounted a good immunological response to the antigens of $S$. choleraesuis. Apparently these protective mechanisms, as well as specific responses to the antigens of $S$. choleraesuis, could not prevent the multiplication of the virulent strain in vaccinated animals.
The deduction may be made that either a lesser degree of immunological activation is required to protect against $S$. typhimurium than against $S$. choleraesuis or that the latter organism is in some other way able to avoid an active specific immune response.

It is unlikely that the virulence of $S$. choleraesuis for mice vaccinated with its aro derivative is mainly due to immunosuppression, because neither $S$. choleraesuis nor $S$. typhimurium after mixed infection grew better in mice thus vaccinated than in those vaccinated with listeria. Moreover, the growth of $S$. typhimurium was suppressed to a greater extent than that of $S$. choleraesuis in mice vaccinated with $S$. choleraesuis aro and challenged simultaneously with both virulent strains. This shows that, even after challenge with virulent $S$. choleraesuis, the mice continued to manifest the augmented tissue bactericidal activity against intracellular bacteria expected after live-vaccine administration.

The mechanism by which $S$. choleraesuis multiplies to kill apparently immunised animals remains unknown. Though able to cause rapidly lethal septicaemia in man and animals, $S$. choleraesuis is readily phagocytosed and killed by mouse peritoneal macrophages in vivo and in vitro. The result is that $<1 \%$ of $S$. choleraesuis or other $\mathrm{O} 6,7$ bacteria injected i.p. are recovered from the liver and spleen after $24 \mathrm{~h}$, compared to $\geqslant 30 \%$ of $\mathrm{O} 4,12$ strains (Nnalue and Stocker, 1987b). The greater virulence of $S$. typhimurium $(0,1,4,12)$ for mice after i.p. injection and its overwhelming predominance in mixed infections of mice is explained, at least in part, by the fact that it is not so readily phagocytosed and killed by peritoneal macrophages. It seems a reasonable deduction that in mice inoculated i.p. with moderate numbers of both organisms (e.g., $6.5 \times 10^{3} \mathrm{cfu}$ of each) most of the $S$. choleraesuis would be rapidly internalised by phagocytic cells while much of the $S$. typhimurium inoculum would remain and multiply extracellularly. As bacteria generally multiply more rapidly extracellularly than intracellularly (Collins, 1979) the non-phagocytosed fraction of an i.p. inoculum of $S$. typhimurium must contribute greatly to the net increase in bacterial numbers in vivo. This implies that mechanisms, immunological or otherwise, that simply enhance phagocytosis, e.g., non-specific resistance, would greatly reduce its virulence. One piece of evidence for the importance of extracellular multiplication for the virulence of $S$. typhimurium UCD108-11 is the fact that replacement of its $O 1,4,12$ antigen with the 06,7 antigen of $S$. choleraesuis $38_{1}$ causes a 10000 -fold reduction in i.p. virulence (Nnalue 
and Stocker, 1987a). The activation of macrophages as a consequence of vaccination, even with unrelated bacteria, should also produce a similar result by reducing or even eliminating the contribution of extracellular multiplication to virulence. Thus, in an immunised mouse most, if not all, of a small inoculum of $S$. choleraesuis or $S$. typhimurium should be quickly phagocytosed after i.p. inoculation. My data therefore agree with theoretical considerations and suggest that $S$. choleraesuis grew better than $S$. typhimurium when most of the bacteria were intracellular and, thus, that it is better adapted for life within mammalian phagocytes. Ability to survive and multiply within phagocytes would seem to be a requirement for an organism such as $S$. choleraesuis that is readily phagocytosed in vivo.

It is of interest that while $>99 \%$ of an i.p. inoculum of $S$. choleraesuis is killed within $24 \mathrm{~h}$, the organism has an i.p. LD50 of $100 \mathrm{cfu}$ in mice. It is very unlikely that a micro-organism could be so virulent by a route in which it is so efficiently destroyed unless the fraction that survived initial killing were sheltered from further bactericidal action and multiplied rapidly. This suggests that even one cfu of $S$. choleraesuis surviving the initial

\section{REFERENCES}

Abernathy R S 1957 Homologous and heterologous resistance in mice given bacterial endotoxins. Journal of Bacteriology 78 : 387-394.

Blanden R V, Mackaness G B, Collins F M 1966 Mechanisms of acquired resistance in mouse typhoid. Journal of Experimental Medicine 124: 585-600.

Carlin N I A, Svenson S B, Lindberg A A 1987 Role of monoclonal O-antigen antibody epitope specificity and isotype in protection against experimental mouse typhoid. Microbial Pathogenicity 2: 171-183.

Cluff L E 1970 Effects of endotoxins on susceptibility to infections. Journal of Infectious Diseases 122 : 205-215.

Collins F M 1968 Cross-protection against Salmonella enteritidis infection in mice. Journal of Bacteriology 95 : 1343-1349.

Collins F M 1979 Cellular antimicrobial immunity. CRC Critical Reviews in Microbiology 7: 27-91.

Colwell D E, Michalek S M, Briles D E, Jirillo E, McGhee J R 1984 Monoclonal antibodies to salmonella lipopolysaccharide: Anti O-polysaccharide antibodies protect $\mathrm{C} 3 \mathrm{H}$ mice against challenge with virulent Salmonella typhimurium. Journal of Immunology 133: 950-957.

Darveau R P, Hancock R E W 1983 Procedure for isolation of bacterial lipopolysaccharides from both smooth and rough Pseudomonas aeruginosa and Salmonella typhimurium strains. Journal of Bacteriology 155 : 831-838.

Eisenstein T K, Killar L M, Stocker B A D, Sultzer B M 1984 Cellular immunity induced by avirulent salmonella in LPSdefective $\mathrm{C} 3 \mathrm{H} / \mathrm{HeJ}$ mice. Journal of Immunology 133: 958961.

Friedman R L, Moon R J 1977 Hepatic clearance of Salmonella typhimurium in silica-treated mice. Infection and Immunity 16: 1005-1012. killing in the peritoneal cavity could multiply to kill a mouse. Published work (Nnalue and Stocker, $1987 b$; Saxen et al., 1987) suggests that antiphagocytic properties play little or no role in the survival and multiplication of $S$. choleraesuis in vivo; thus, antimicrobial mechanisms that simply increase the rate of phagocytosis should have little effect on the outcome of infection. The perfused rat or mouse liver can trap bacteria extracellularly within sinusoids (Moon et al., 1975) and both Kupfer and endothelial cells can trap salmonellae (Friedman and Moon, 1977). An interesting question is whether, despite its efficient killing by macrophages, $S$. choleraesuis remains virulent for vaccinated mice because it can invade cells that lack bactericidal properties or can multiply extracellularly at sites within the liver and spleen not accessible to cellular infiltration. This organism offers a unique experimental tool for investigation of the strategies of microbial persistence and growth in an immunised host as well as of host mediation systems against intracellular parasites.

I thank Dr B. Stocker for the material and moral support for this work and U. Forsum and D Verma for critical reading of the manuscript.

Griffith R W, Kramer T T 1982 Sensitivity of smooth Salmonella choleraesuis var. Kunzendorf field strains to antibody and complement under various conditions. American Journal of Veterinary Research 43: 1413-1417.

Herzberg M, Nash P, Hino S 1972 Degree of immunity induced by killed vaccines to experimental salmonellosis. Infection and Immunity 5 : 83-90.

Hochadel J F, Keller K F 1977 Protective effects of passively transferred immune $\mathrm{T}$ or B lymphocytes in mice infected with Salmonella typhimurium. Journal of Infectious Diseases 135: 813-823.

Huang C T, Lo C B 1967 Human infections with Salmonella choleraesuis in Hong Kong. Journal of Hygiene 65: 149-163.

Kuusi N, Nurminen M, Saxen H, Valtonen M, Mäkelä P H 1979 Immunization with major outer membrane proteins in experimental salmonellosis of mice. Infection and Immunity 25 : $857-862$.

Levine M M, Hornick R B 1981 Immunology of enteric pathogens: Salmonella, Shigella and Escherichia coli. In: Nahmias A J, O'Reilly R J (eds) Immunology of human infection. Part I: Bacteria, mycoplasmae, chlamydias and fungi. (Comprehensive Immunology 8). Plenum, New York, pp 249-290.

Liang-Takasaki C J, Grossman N, Leive L 1983 Salmonellae activate complement differentially via the alternate pathway depending on the structure of their lipopolysaccharide O-antigen. Journal of Immunology 130 : 1867-1870.

Liang-Takasaki C J, Mäkelä P H, Leive L 1982 Phagocytosis of bacteria by macrophages: changing the carbohydrate of lipopolysaccharide alters the interaction with complement and macrophages. Journal of Immunology 128: 1229-1235.

Lindberg A A, Rosenberg L T, Ljunggren A, Garegg P J, Svensson S, Wallin N-H 1974 Effect of synthetic disacchar- 
ide protein conjugate as an immunogen in salmonella infection in mice. Infection and Immunity 10: 541-545.

Lyman M B, Stocker B A D, Roantree R J 1979 Evaluation of the immune response directed against salmonella antigenic factors $\mathrm{O} 4,5$ and $\mathrm{O} 9$. Infection and Immunity 26: 956-965.

MacCready R A, Reardon J P, Saphra I 1957 Salmonellosis in Massachusets: a sixteen-year experience. New England Journal of Medicine 256: 1121-1128.

Mackaness G B 1964 The immunological basis of acquired cellular resistance. Journal of Experimental Medicine 120: 105-120.

McCabe W R 1972 Immunisation with R mutants of $S$. minnesota. I. Protection against challenge with heterologous gram negative bacilli. Journal of Immunology 108: 601-610.

McCabe W R, Johns M A, Craven D E, Bruins S C 1977 Clinical implications of enterobacterial antigens. In : Schlessinger D (ed) Microbiology. American Society for Microbiology, Washington DC. pp 293-297.

Moon R J, Vrable R A, Broka J A 1975 In-situ separation of bacterial trapping and killing functions of the perfused liver. Infection and Immunity 12: 411-418.

Morrison D C, Ulevitch R J 1978 The effect of bacterial endotoxins on host mediation systems. American Journal of Pathology 93: 526-617.

Nnalue N A, Stocker B A D 1986 Some galE mutants of Salmonella choleraesuis retain virulence. Infection and Immunity 54: 635-640.

Nnalue N A, Stocker B A D $1987 a$ Test of the virulence and live-vaccine efficacy of auxotrophic and galE derivatives of Salmonella choleraesuis. Infection and Immunity 55:955-962.

Nnalue N A, Stocker B A D $1987 b$ The effects of O-antigen character and enterobacterial common antigen content on the in-vivo persistence of aromatic-dependent Salmonella sp. live-vaccine strains. Microbial Pathogenesis 3: 31-44.

Ornellas E P, Roantree R J, Steward J P 1970 The specificity and importance of humoral antibody in the protection of mice against intraperitoneal challenge with complementsensitive and complement-resistant salmonella. Journal of Infectious Diseases 121 : 113-123.

Ornellas E P, Stocker B A D 1974 Relation of lipopolysaccharide character to $\mathrm{Pl}$ sensitivity in Salmonella typhimurium. Virology 60: 491-502.

Saphra I, Winter J W 1957 Clinical manifestations of salmonellosis in man: an evaluation of 7779 human infections identified at the New York Salmonella center. New England Journal of Medicine 256: 1128-1134.
Saxen H, Reima I, Mäkelä P H 1987 Alternative complement pathway activation by salmonella $O$ polysaccharide as a virulent determinant in the mouse. Microbial Pathogenesis 2: $15-28$.

Schlecht S 1981 Active immunization to experimental salmonellosis in mice. Protective properties of salmonella $\mathbf{R}$ mutants against infection with different pathogenic Salmonella species. Zentralblatt für Bakteriology und Hygiene I Abt. Orig. A 249: 362-372.

Smith B P et al. 1984 Aromatic-dependent Salmonella typhimurium as modified live-vaccines for calves. American Journal of Veterinary Research 45: 59-66.

Smith H W, Halls S 1966 The immunity produced by a rough Salmonella dublin variant against Salmonella typhimurium and Salmonella choleraesuis infection in guinea pigs. Journal of Hygiene 64: 357-359.

Smith H W 1965 The immunization of mice, calves and pigs against Salmonella dublin and Salmonella choleraesuis infections. Journal of Hygiene 63: 117-135.

Svenson S B, Nurminen M, Lindberg A A 1979 Artificial salmonella vaccines: O-antigenic oligosaccharide-protein conjugates induce protection against infection with Salmonella typhimurium. Infection and Immunity 25: 863-872.

Valtonen M V 1977 Role of phagocytosis in mouse virulence of Salmonella typhimurium recombinants with $\mathrm{O}$-antigen 6,7 or 4,12. Infection and Immunity 18: 574-582.

Valtonen M V, Plosila M, Valtonen V V, Mäkelä P H 1975 Effect of the quality of the lipopolysaccharide on mouse virulence of Salmonella enteritidis. Infection and Immunity 12: 828-832.

Vuopio-Varkila J, Nurminen M, Phyälä L, Mäkelä P H 1988 Lipopolysaccharide-induced non-specific resistance to systemic Escherichia coli infection in mice. Journal of Medical Microbiology 25: 197-203.

Weissbluth M, Shulman S T, Holson B, Lerner C 1981 Salmonella cholerae-suis: a distinctive bacterial pathogen. Journal of Pediatrics 98: 423-426.

Wong J C S, Kucera C J 1982 Cross-protection by a chemically altered vaccinal strain of Pasteurella multocida in mice and hamsters. American Journal of Veterinary Research 43: 13151316.

Zinkernagel R M 1976 Cell-mediated immune response to Salmonella typhimurium infection in mice: development of nonspecific bactericidal activity against Listeria monocytogenes. Infection and Immunity 13: 1069-1073. 